\title{
Is chronic ventilatory support really effective in patients with amyotrophic lateral sclerosis?
}

\author{
A. Hazenberg ${ }^{1,2,3}$ (D) H. A. M. Kerstjens ${ }^{1,2,3}$ - S. C. L. Prins ${ }^{4}$ - K. M. Vermeulen ${ }^{5}$. \\ P. J. Wijkstra ${ }^{1,2,3}$
}

Received: 8 July 2016/Revised: 8 September 2016/Accepted: 9 September 2016/Published online: 16 September 2016

(C) The Author(s) 2016. This article is published with open access at Springerlink.com

\begin{abstract}
Most patients with amyotrophic lateral sclerosis (ALS) develop respiratory insufficiency in the advanced stage of their disease. Non-invasive ventilation (NIV) is commonly regarded to be a treatment that is effective in reducing these complaints. To assess whether the effect of NIV on gas exchange and quality of life (QOL) is different in patients with ALS versus without ALS. A post hoc analysis was done with data from a previously published trial, in which all patients were instituted on NIV. Arterial blood gasses were assessed next to QOL by generic as well as disease-specific questionnaires. 77 patients started NIV: 30 with ALS and 47 without. Both groups showed significant improvements in blood gasses after 2 and 6 months. Compared to the non-ALS group, the ALS group had significantly worse scores after 6 months in MRF-28, SRI, HADS and SF-36 than the non-ALS group. This study shows that NIV improves gas exchange, both in patients with and without ALS. QOL improves markedly more in
\end{abstract}

A. Hazenberg

a.hazenberg@umcg.nl

1 Department of Home Mechanical Ventilation, University of Groningen, University Medical Center Groningen, Groningen, The Netherlands

2 Department of Pulmonology and Tuberculosis, University of Groningen, University Medical Center Groningen, Groningen, The Netherlands

3 University Medical Center Groningen, GRIAC Research Institute, University of Groningen, Groningen, The Netherlands

4 TNO, The Netherlands Organization for Applied Scientific Research, The Hague, The Netherlands

5 Department of Epidemiology, University of Groningen, University Medical Center Groningen, Groningen, The Netherlands patients without ALS than in those with ALS, in whom only some domains improve. Our observation of little or no effect in ALS patients warrants a large study limited to ALS patients only.

Keywords Amyotrophic lateral sclerosis · Quality of life · Non-invasive ventilation

\section{Introduction}

Most patients with amyotrophic lateral sclerosis (ALS) develop complaints of dyspnea, fatigue, unrefreshing sleep and morning headache in the advanced stage of their disease due to respiratory insufficiency. Chronic ventilatory support is commonly regarded to be a treatment that is effective in reducing these complaints.

Several studies presented data regarding the effects of chronic ventilatory support on quality of life (QOL) in patients with ALS. Some were positive, while others produced more reservations regarding chronic ventilatory support in these patients. In 2001, in a prospective study, QOL following noninvasive ventilation (NIV) was assessed with two questionnaires, the ALS functional rating scale-respiratory version (ALSFRS-R) and the Short Form 36 (SF-36) [1]. Early intervention of NIV resulted in an improved vitality compared to standard care in this study. In 2003, Bourke et al. presented the results of a cohort study on indications and effect of NIV on QOL in ALS patients. They used the SF-36 to assess QOL in 10 participants using NIV. In this study, the use of NIV was associated with an improved QOL and survival [2]. Finally, a third cohort study on the effects of NIV on ALS patients showed that one month after starting chronic ventilatory support, both blood gasses and QOL improved [3]. In 2006, Bourke assessed the effect of NIV, QOL and survival in 
participants with ALS in a randomized controlled trial [4]. Their conclusion was that NIV use in patients without bulbar dysfunction was associated with an improved QOL in some domains and a longer maintained QOL above $75 \%$ of the prerandomization QOL assessed by SF-36. Despite the results mentioned above, Piepers et al. concluded in their review that these studies on the use of NIV in patients with ALS differ considerably in design and endpoint definitions and that welldesigned randomized controlled trials are, to their opinion, not available [5].

We agree with the notion that more well-designed studies are needed on the effect of chronic ventilatory support in relation to QOL in patients with ALS. An additional point of concern is that in most studies, only the generic SF-36 has been used, while questionnaires set up specifically to assess quality of life in patients with respiratory insufficiency like the Maugeri Respiratory Failure (MRF-28) and the Severe Respiratory Insufficiency (SRI) were not used at all. Also, we believe that it is unfortunate that the previous studies did not report on outcomes like depression and anxiety, items frequently mentioned by patients with ALS.

In a randomized controlled study assessing the effect on QOL of home versus in-hospital initiation of NIV in patients with a neuromuscular disorder (NMD) or thoracic cage problem, we showed an overall improvement of QOL after the start of NIV [6]. However, in this study, the effect size in separate diagnostic groups, such as ALS, was not assessed. It was, however, unique in the sense that not only the SF-36, but both the SRI and MRF-28 were used to assess QOL, as was the Hospital Anxiety and Depression Scale (HADS). By doing so, we created a broader perspective on QOL than with only the SF-36. In the present analysis, we hypothesized that the effect of NIV on QOL in patients with ALS, as assessed by the SF-36, SRI, MRF-28 and HADS questionnaires, is different compared to patients with other reasons for need of NIV.

\section{Methods}

A post hoc analysis was performed in all patients who started with NIV, from a previously published randomized controlled trial [6]. Patients, who had been diagnosed with chronic respiratory failure due to a neuromuscular disorder (NMD) or a thoracic cage problem, were included. The study was approved by the Medical Ethics Committee of the University of Groningen, University Medical Center of Groningen, and written informed consent was obtained from all patients. Chronic respiratory failure was defined as daytime arterial carbon dioxide pressure $\left(\mathrm{PaCO}_{2}\right)>6.0 \mathrm{kPa}$ $(>45 \mathrm{mmHg})$. Participants started NIV at home or in the hospital in a randomized design. In line with our hypothesis and reassuringly, the results for gas exchange and QOL were not significantly different between patients who started in the hospital versus at home [7]. In the current analysis, we pooled all patients without ALS in one group and compared it to those with ALS. Gas exchange was assessed by daytime arterial blood gasses from the radial artery, and the following self-administered questionnaires were completed: SRI [8], MRF-28 [9], the SF-36 [10] and the HADS [11]. The SRI contains seven domains covering: respiratory complaints, physical functioning, attendant symptoms and sleep, social relationship, anxiety, psychological well-being and social functioning. Scores range between 0 and 100, with high sores representing better quality of life. The MRF-28 contains three domains: daily activities, cognitive function and invalidity; scores range from 0 (best) to 100 (worse). The SF36 contains eight domains: physical functioning, role physical, bodily pain, general health, vitality, social functioning, role emotional and mental health completed with the physical and mental component summary score 0 (worse) to 100 (best) [12]. The HADS contains the anxiety and depression domain; scores range from 0 (best) tot 42 (worse).

\section{Statistical analyses}

Independent-sample $t$ tests were used to test for differences in change $(\Delta)$ between groups from baseline to 6 months, and paired sample $t$ tests were performed to assess the change within groups from baseline to 2 and 6 months. The level of statistical significance was set at $p<0.05$. Statistical analyses were performed using IBM Statistics 22 (IBM, New York, USA).

\section{Results}

77 participants were randomized to start NIV at home or in the University Medical Center of Groningen (UMCG). For this manuscript, both groups were pooled since there were no differences between the results in both intervention arms, as per prior hypothesis. Thirty participants had ALS (grouped as ALS), the other 47 participants had a neuromuscular disease (diaphragm paralysis, myotonic dystrophy, limb girdle muscular dystrophy, facioscapulohumeral dystrophy and other) or a thoracic cage problem (kyphoscoliosis or obesity hypoventilation syndrome) (grouped as non-ALS). The baseline characteristics are presented in Table 1 and show that both groups were comparable in age and gas exchange. NIV was initiated in the ALS group a median of 427 (22-2582) days after being diagnosed with ALS. Median survival in the ALS group after the initiation of NIV was 461 (220-1451) days; none of the participants was still alive at the moment of our investigation. Eight patients in each group withdrew during follow-up, mainly due to worsening of their disease, death 
Table 1 Baseline characteristics

\begin{tabular}{lll}
\hline & ALS group, $n=30$ & Non-ALS group, $n=47$ \\
\hline Diagnosis & Amyotrophic lateral sclerosis & $\begin{array}{l}\text { Neuromuscular disease }(n=42) \\
\text { Thoracic cage problem }(n=5)\end{array}$ \\
Age (years) & $59.6 \pm 10.6$ & $57.7 \pm 14.7$ \\
Male $(\%)$ & 66.7 & 53.2 \\
$\mathrm{PaCO}_{2}(\mathrm{kPa})$ & $6.6 \pm 0.8$ & $6.6 \pm 1.0$ \\
$\mathrm{PaO}_{2}(\mathrm{kPa})$ & $10.4 \pm 0.9$ & $9.6 \pm 1.6$ \\
$\mathrm{BMI}\left(\mathrm{kg} / \mathrm{m}^{2}\right)$ & $23.8 \pm 5.2$ & $28.9 \pm 6.4$ \\
Packyears & $27.8 \pm 19.4$ & $18.9 \pm 14.4$ \\
\hline
\end{tabular}

Data are presented as mean \pm standard deviation

$k \mathrm{~Pa}$ kilo Pascal, $\mathrm{PaCO}_{2}$ partial pressure of arterial carbon dioxide, $\mathrm{PaO}_{2}$ partial pressure of arterial oxygen, $B M I$ body mass index

Table 2 Changes in daytime arterial blood gasses, lung function, hours of non-invasive ventilation and transcutaneous carbon dioxide and oxygen saturation after the start of non-invasive ventilation

\begin{tabular}{|c|c|c|c|c|c|c|c|}
\hline & \multicolumn{3}{|l|}{ ALS group } & \multicolumn{3}{|c|}{ Non-ALS group } & \multirow{2}{*}{$\begin{array}{l}\text { Between groups } \\
P \text { value for } \\
\text { difference in } \\
\text { change } 0-6 \text { months }\end{array}$} \\
\hline & $\begin{array}{l}\text { Baseline, } \\
N=30\end{array}$ & $\begin{array}{l}\text { Change } 0-2 \\
\text { months } \\
(N=12)\end{array}$ & $\begin{array}{l}\text { Change } 0-6 \\
\text { months } \\
(N=19)\end{array}$ & $\begin{array}{l}\text { Baseline } \\
(N=47)\end{array}$ & $\begin{array}{l}\text { Change } \\
0-2 \text { months } \\
(N=17)\end{array}$ & $\begin{array}{l}\text { Change } \\
0-6 \text { months } \\
(N=43)\end{array}$ & \\
\hline $\mathrm{PaCO}_{2}(\mathrm{kPa})$ & $6.6 \pm 0.8$ & $-1.2 \pm 0.4^{*}$ & $-0.7 \pm 0.3^{*}$ & $6.6 \pm 1.0$ & $-1.1 \pm 0.2 *$ & $-0.7 \pm 0.2^{*}$ & 0.862 \\
\hline $\mathrm{PaO}_{2}(\mathrm{kPa})$ & $10.4 \pm 0.9$ & $1.8 \pm 0.7^{*}$ & $0.3 \pm 0.4$ & $9.6 \pm 1.6$ & $0.3 \pm 0.7^{*}$ & $1.3 \pm 0.3^{*}$ & $0.035^{\bullet}$ \\
\hline FVC (\% pred) & $41.6 \pm 13.7$ & - & $-9.8 \pm 3.7^{*}$ & $45.2 \pm 16.6$ & - & $2.5 \pm 2.1$ & $0.005^{\bullet}$ \\
\hline \multirow[t]{2}{*}{ FEV1 \% FVC } & $88.1 \pm 13.8$ & - & $-3.2 \pm 3.4$ & $76.2 \pm 12.3$ & - & $3.0 \pm 2.9$ & 0.247 \\
\hline & $\begin{array}{l}\text { NIV initiated, } \\
N=28\end{array}$ & $N=27$ & $N=23$ & $\begin{array}{l}\text { NIV initiated, } \\
N=46\end{array}$ & $N=43$ & $N=42$ & \\
\hline Hours NIV & $7.7 \pm 3.8$ & $3.5 \pm 1.3^{*}$ & $3.8 \pm 1.5^{*}$ & $6.8 \pm 1.7$ & $0.9 \pm 0.4^{*}$ & $1.1 \pm 0.4^{*}$ & 0.031 \\
\hline $\operatorname{tcpCO}_{2}(\mathrm{kPa})$ & $6.5 \pm 0.9$ & $-1.6 \pm 0.3^{*}$ & $-2.5 \pm 0.4$ & $6.4 \pm 0.9$ & $-1.5 \pm 0.2 *$ & $-1.7 \pm 0.3^{*}$ & 0.111 \\
\hline $\operatorname{tcSpO}_{2}(\%)$ & $95.9 \pm 1.5$ & $3.3 \pm 0.4$ & $3.8 \pm 0.5^{*}$ & $95.1 \pm 1.7$ & $6.1 \pm 1.0^{*}$ & $6.0 \pm 1.1^{*}$ & 0.103 \\
\hline
\end{tabular}

Baseline data are presented as mean \pm standard deviation

Changes over time are presented as mean \pm standard error of mean

$k \mathrm{~Pa}$ kilo Pascal, $\mathrm{PaCO}_{2}$ partial pressure of arterial carbon dioxide, $\mathrm{PaO}_{2}$ partial pressure of arterial oxygen, $F V C$ forced vital capacity, $F E V_{1}$ forced expiratory volume in one second, \%pred \% predicted, $\mathrm{NIV}$ non-invasive ventilation, $t c p \mathrm{CO}_{2}$ transcutaneous carbon dioxide, $t c S p \mathrm{O}_{2}$ transcutaneous oxygen saturation

- $p<0.05$ : for difference in change between groups 0-6 months

$* p<0.05$ for chances within groups from baseline

or noncompliance with NIV [6]. Both groups showed an improvement in arterial and transcutaneous $\mathrm{CO}_{2}$ and $\mathrm{O}_{2}$, after 2 and 6 of NIV (Table 2); however, the mean improvements in arterial and transcutaneous $\mathrm{CO}_{2}$ were not significantly different between the groups. The mean improvement in $\mathrm{PaO}_{2}$ after 6 months was significantly lower in the non-ALS group compared to the ALS group. The mean number of hours on NIV increased over time in both groups. The ALS group used NIV for more than $11 \mathrm{~h}$ after 6 months and the other group $8 \mathrm{~h}$ per day (between group difference in change after 6 months $p=0.03$ ). Some patients used NIV $24 \mathrm{~h}$ per day, depending on the progression of their disease. Forced vital capacity (FVC) showed a significant difference between both groups after
6 months as in the ALS group, the FVC decreased significantly, whereas the FVC in the non-ALS group improved slightly (Table 2). At baseline, quality of life was higher in the non-ALS group than in the ALS group. Compared to the non-ALS group, the ALS group showed significantly less improvement after 6 months on the MRF-28 total score. (Fig. 1; Table 3). The sum score of the MRF-28, SRI, HADS and SF-36 improved significantly in the nonALS group after 6 months, whilst in the ALS group, only the sum score of theSF-36 improved significantly after 6 months (Table 3). QOL in the ALS group even deteriorated as expressed by the sum scores of the MRF-28, SRI and HADS, leading to significant differences between groups after 6 months. 

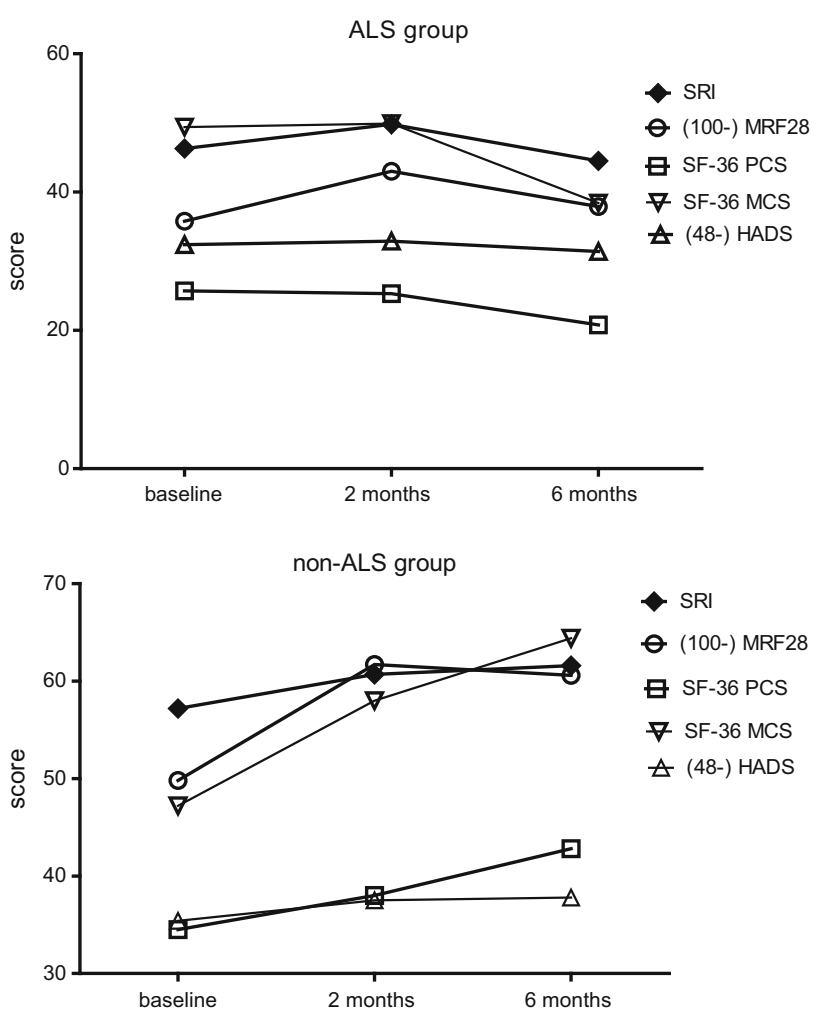

Fig. 1 Quality-of-life measurement from baseline till 6 months after the start of chronic ventilatory support. $A L S$ amyotrophic lateral scleroses, $N I V$ non-invasive ventilation, $S R I$ severe respiratory insufficiency $(0=$ worst possible health; $100=$ best possible health $)$, MRF-28 Maugeri Respiratory Failure $(0=$ best possible health; $100=$ worst possible health), SF-36 Short-Form Health Status Survey $(0=$ worst possible health; $100=$ best possible health), $S F$ 36 PCS physical component score, SF-36 MCS mental component score, HADS Hospital Anxiety and Depression Scale $(0=$ best possible score; $48=$ worst possible score)

Both groups showed significant improvements on the attendant symptoms and sleep domain of the SRI which improved significantly in both groups. Within the non-ALS group, many domains improved significantly after both 2 and 6 months. By contrast, in the ALS group, only three domains of the SRI improved significantly after 2 and 6 months; only the attendant symptoms and sleep domain of the SRI were still significantly improved in the ALS group as compared to baseline. Two domains of the SRI, social functioning and social relationship, worsened significantly in the ALS group, showing also a significant difference between both groups.

\section{Discussion}

In this study, NIV was effective in improving gas exchange in both the ALS and the non-ALS group after 2 and 6 months. While NIV also clearly improved QOL in the non-ALS patients, the patients with ALS showed a different pattern. After 2 months, only three domains of the SRI questionnaire improved significantly. More importantly, quality of life became even worse in patients diagnosed with ALS as compared to the non-ALS group after 6 months of NIV.

More than 150 patients start chronic ventilatory support every year at the Department of Home Mechanical Ventilation of our hospital. Patients visit the outpatient clinic before starting chronic ventilatory support. Until now, we advised ALS patients to start chronic ventilatory support mainly based on the premise of a longer maintained QOL or even improved QOL in the randomized controlled trial of Bourke [13]. While different assessments on different moments were used, our study showed that after 2 months of NIV, QOL was maintained above $75 \%$ of baseline in both groups. After 6 months, the domains physical functioning, role physical and role emotional of the SF-36 and physical functioning and social functioning of the SRI were under $75 \%$ of baseline in the ALS group. Our group differs from that of Bourke et al., in that patients in the Bourke study had higher vital capacity and lower starting carbon dioxide at baseline compared to our study. In the Bourke study, there was a mean of 710 days after the first onset of weakness in any muscle before starting NIV. This suggests a similar moment of starting NIV in both studies, as the mean before the start of NIV in our study was 686 days. Our limited results in ALS were not the result of a bulbar impairment as gas exchange improved, and more importantly, only 2 out of 30 patients had a bulbar problem. Most importantly, however, we have to take into account that we did not include a control group with ALS but no NIV in contrast to Bourke, and therefore, could not assess if the NIV group was worse compared to a control group. There were also important other differences between the Bourke study and ours in the assessment of QOL. The SRI and the MRF-28 questionnaires were specifically developed for patients with respiratory failure and, therefore, used in our study, next to the HADS and SF-36. It is remarkable to see that after 6 months of chronic ventilatory support in the ALS group, only the SRI domain attendant symptoms and sleep significantly improved. In contrast, the sum score of the SRI, MRF-28 and HADS improved significantly in the non-ALS group. We think that progression of the disease ALS is one of the reasons that most domains do not improve.

Routinely, during a house call visit after a patient with ALS has died, we ask next of kin or caregivers to share their experiences with us. In general, we are told they are satisfied with the level of care and result of the therapy, comfort during sleep and more awake during daytime. However, during the last months of their life, these benefits disappear as leakage of the mask during ventilation becomes a burden for both the patient and relatives. The 
Table 3 Changes in quality-of-life measurements after the start of non-invasive ventilation

\begin{tabular}{|c|c|c|c|c|c|c|}
\hline \multicolumn{3}{|l|}{ ALS group } & \multicolumn{3}{|c|}{ Non-ALS group } & \multirow{2}{*}{$\begin{array}{l}\text { Between } \\
\text { groups } \\
P \text { value for } \\
\text { difference in } \\
\text { change } 0-6 \\
\text { months }\end{array}$} \\
\hline $\begin{array}{l}\text { Baseline, } \\
N=29\end{array}$ & $\begin{array}{l}\text { Change } \\
0-2 \text { months, } \\
N=26\end{array}$ & $\begin{array}{l}\text { Change } \\
0-6 \text { months, } \\
N=22\end{array}$ & $\begin{array}{l}\text { Baseline, } \\
N=47\end{array}$ & $\begin{array}{l}\text { Change } \\
0-2 \text { months, } \\
N=41\end{array}$ & $\begin{array}{l}\text { Change } 0-6 \\
\text { months, } \\
N=43\end{array}$ & \\
\hline
\end{tabular}

\begin{tabular}{|c|c|c|c|c|c|c|c|}
\hline \multicolumn{8}{|l|}{ SRI } \\
\hline Respiratory complaints & $42.0 \pm 16.8$ & $6.7 \pm 3.0^{*}$ & $2.0 \pm 4.2$ & $51.9 \pm 19.5$ & $9.7 \pm 2.0$ & $7.3 \pm 2.0^{*}$ & 0.194 \\
\hline Physical functioning & $21.0 \pm 18.4$ & $-3.0 \pm 2.8$ & $-7.9 \pm 4.5$ & $40.0 \pm 19.7$ & $2.9 \pm 2.1$ & $1.8 \pm 3.0$ & 0.075 \\
\hline Attendant symptoms/sleep & $49.5 \pm 14.6$ & $15.2 \pm 3.4^{*}$ & $15.6 \pm 4.1^{*}$ & $53.3 \pm 21.3$ & $6.5 \pm 2.3$ & $11.4 \pm 2.5^{*}$ & 0.363 \\
\hline Social relationship & $68.2 \pm 10.2$ & $-0.6 \pm 2.1$ & $-6.3 \pm 1.7^{*}$ & $70.9 \pm 13.8$ & $1.2 \pm 2.0$ & $1.3 \pm 2.3$ & $0.032^{\top}$ \\
\hline Anxiety & $47.4 \pm 12.1$ & $6.9 \pm 2.7 *$ & $-6.4 \pm 4.2$ & $59.5 \pm 21.0$ & $4.3 \pm 2.5$ & $9.0 \pm 2.6^{*}$ & $0.002^{\oplus}$ \\
\hline Well-being & $51.2 \pm 17.4$ & $1.8 \pm 2.6$ & $0.4 \pm 2.8$ & $63.5 \pm 16.6$ & $1.0 \pm 2.0$ & $-0.1 \pm 1.9$ & 0.899 \\
\hline Social functioning & $44.5 \pm 13.7$ & $-2.7 \pm 2.5$ & $-7.1 \pm 3.0^{*}$ & $61.5 \pm 18.0$ & $1.4 \pm 2.0$ & $1.1 \pm 2.1$ & $0.027^{\bullet}$ \\
\hline Summary score & $46.3 \pm 8.7$ & $3.5 \pm 1.8$ & $-1.4 \pm 2.4$ & $57.2 \pm 14.0$ & $3.9 \pm 1.3^{*}$ & $4.5 \pm 1.6^{*}$ & $0.037^{\bullet}$ \\
\hline \multicolumn{8}{|l|}{ MRF-28 } \\
\hline Daily activities & $74.0 \pm 24.9$ & $4.1 \pm 2.4$ & $5.4 \pm 5.7$ & $51.8 \pm 29.2$ & $-8.7 \pm 3.6$ & $-7.4 \pm 4.3$ & 0.083 \\
\hline Cognition & $34.5 \pm 33.0$ & $-9.6 \pm 6.2$ & $-4.1 \pm 6.2$ & $37.8 \pm 34.9$ & $-9.7 \pm 4.6^{*}$ & $-7.6 \pm 4.8$ & 0.675 \\
\hline Invalidity & $73.1 \pm 31.7$ & $-2.3 \pm 6.0$ & $2.7 \pm 5.8$ & $44.2 \pm 35.1$ & $-2.9 \pm 5.0$ & $4.2 \pm 5.5$ & 0.867 \\
\hline Total score & $64.2 \pm 17.9$ & $-4.7 \pm 2.4$ & $-1.4 \pm 4.2$ & $50.2 \pm 22.1$ & $-13.0 \pm 2.9^{*}$ & $-11.9 \pm 2.9 *$ & $0.041^{\bullet}$ \\
\hline \multicolumn{8}{|l|}{ HADS } \\
\hline Depression & $8.3 \pm 7.2$ & $-0.2 \pm 0.6$ & $1.0 \pm 0.6$ & $6.3 \pm 3.8$ & $-1.3 \pm 0.4^{*}$ & $-1.6 \pm 0.4^{*}$ & $0.001^{\top}$ \\
\hline Anxiety & $7.3 \pm 4.3$ & $0.2 \pm 0.6$ & $0.8 \pm 0.7$ & $6.3 \pm 4.0$ & $-1.2 \pm 0.5^{*}$ & $-1.1 \pm 0.4^{*}$ & $0.017^{\bullet}$ \\
\hline Total score & $15.6 \pm 7.2$ & $-0.0 \pm 1.1$ & $1.8 \pm 1.1$ & $12.6 \pm 7.2$ & $-2.5 \pm 0.8^{*}$ & $-2.7 \pm 0.7^{*}$ & $0.001^{\top}$ \\
\hline \multicolumn{8}{|l|}{ SF-36 } \\
\hline Physical functioning & $10.3 \pm 17.6$ & $-1.0 \pm 1.4$ & $-7.1 \pm 3.2^{*}$ & $18.2 \pm 21.5$ & $4.0 \pm 1.3^{*}$ & $4.4 \pm 2.0^{*}$ & $0.002^{\top}$ \\
\hline Role physical & $6.0 \pm 12.7$ & $1.9 \pm 4.6$ & $-4.8 \pm 3.3$ & $19.7 \pm 34.9$ & $6.1 \pm 6.0$ & $17.4 \pm 7.0^{*}$ & $0.036^{\top}$ \\
\hline Bodily pain & $66.9 \pm 25.4$ & $-3.8 \pm 5.0$ & $-11.4 \pm 7.4$ & $64.8 \pm 32.5$ & $-0.3 \pm 4.4$ & $3.0 \pm 4.1$ & 0.071 \\
\hline General health & $19.6 \pm 13.6$ & $-0.3 \pm 3.1$ & $-3.0 \pm 2.8$ & $37.2 \pm 22.4$ & $2.5 \pm 2.6$ & $7.6 \pm 3.1^{*}$ & $0.031^{\top}$ \\
\hline Vitality & $33.6 \pm 17.3$ & $3.1 \pm 3.9$ & $4.3 \pm 4.0$ & $40.4 \pm 21.4$ & $10.6 \pm 3.1^{*}$ & $13.3 \pm 2.7^{*}$ & 0.065 \\
\hline Social functioning & $44.4 \pm 27.7$ & $2.9 \pm 6.3$ & $-13.6 \pm 5.9 *$ & $59.8 \pm 26.5$ & $4.6 \pm 3.7$ & $11.3 \pm 4.0^{*}$ & $0.001^{\top}$ \\
\hline Role emotional & $59.8 \pm 45.7$ & $-1.3 \pm 12.8$ & $-14.3 \pm 8.5$ & $46.1 \pm 51.3$ & $13.0 \pm 9.4$ & $20.9 \pm 9.1 *$ & $0.017^{\bullet}$ \\
\hline Mental health & $64.4 \pm 20.4$ & $-0.5 \pm 2.4$ & $0.5 \pm 3.2$ & $66.2 \pm 19.4$ & $6.0 \pm 2.0^{*}$ & $8.6 \pm 2.5^{*}$ & 0.050 \\
\hline Physical component summary & $25.7 \pm 10.2$ & $-0.8 \pm 2.3$ & $-6.8 \pm 2.4^{*}$ & $34.5 \pm 16.7$ & $3.1 \pm 2.1$ & $8.1 \pm 2.8^{*}$ & $0.001^{\top}$ \\
\hline Mental component summary & $49.4 \pm 28.2$ & $1.0 \pm 7.6$ & $-9.5 \pm 5.3$ & $47.2 \pm 31.8$ & $10.3 \pm 5.6$ & $16.6 \pm 5.5^{*}$ & $0.004^{\top}$ \\
\hline
\end{tabular}

Baseline data are presented as mean \pm standard deviation

Change over time are presented as mean \pm standard error of mean

- $p<0.05$ for difference in change between groups 0-6 months

$* p<0.05$ for changes within groups from baseline

SRI Severe Respiratory Insufficiency $(0=$ worst possible health; $100=$ best possible health $), M R F-28$ Maugeri Respiratory Failure $(0=$ best possible health; $100=$ worst possible health), HADS Hospital Anxiety Depression Scale $(0=$ best possible score; $42=$ worst possible score), $S F-36$ Short-Form Health Status Survey $(0=$ worst possible health; $100=$ best possible health $)$

sound of air leaking by the mask and the ventilator wakes everybody, and does not provide any comfort anymore. We sometimes hear relatives make the remark that after the patient has died, it was a relief to see them lying in bed without mask and ventilatory support. These facts are worthwhile to consider and should be shared with patients before the start of HMV.
A limitation of our study is that it was primarily set up as a randomized controlled trial, comparing initiation of NIV at home with an in-hospital start irrespective of diagnosis and, therefore, not to compare specifically ALS to non-ALS patients. Comparing patients with and without ALS is, from a life-expectancy perspective, imperfect and should be done with caution. To understand the results of 
the ALS group in a broader perspective, in a future study, patients with ALS should be randomized to receive NIV or not. However, starting a randomized controlled trial, one group with NIV and one group without, is probably, from an ethical perspective, not easy to realize, because NIV has become the cornerstone of symptom management in patients with ALS.

Second, the ALS group had a smaller size than the nonALS group resulting in lower chance of finding significant within group results compared to the non-ALS group.

In conclusion, our study shows that NIV improves blood gasses in a wide range of patients, with or without ALS. However, in patients with ALS, QOL did not improve after 6 months of NIV relative to baseline, and some domains (social functioning, social relationship and physical functioning) even showed a significant deterioration compared to baseline.

Given the doubt we create on the results of NIV in patients with ALS, we believe that prospective studies are warranted in ALS patients with proper randomized controlled setup for this question, using disease-specific QOL questionnaires.

With regard to the other studies, we think that in our study, chronic ventilatory support was initiated in a more advanced stage of the disease. Therefore, we believe that these results raise questions about the efficacy of NIV in these specific patients, but they need to be confirmed in a future dedicated randomized controlled trial in ALS patients using similar quality-of-life questionnaires.

Acknowledgments We are very grateful to all the patients, their family members and the homecare professionals who kindly agreed to participate in this study and to everyone who worked on this project. We would also like to thank the members of the Data Safety Monitoring Board; Prof. Dr. J. G. Zijlstra, Prof. Dr. E. R. van den Heuvel (University Medical Center Groningen) and Mw. Drs. A. F. Meinesz for their contribution.

\section{Complaince with eithical standards}

Conflicts of interest This study was financially supported by the Health Care Insurance Board in the Netherlands, the University Medical Center Groningen, Vivisol Area UK \& Benelux and ResMed.

Ethical standards This study was performed in accordance with the ethical standards laid down in the 1964 Declaration of Helsinki and its later amendments.

Open Access This article is distributed under the terms of the Creative Commons Attribution 4.0 International License (http://creativecommons.org/licenses/by/4.0/), which permits unrestricted use, distribution, and reproduction in any medium, provided you give appropriate credit to the original author(s) and the source, provide a link to the Creative Commons license, and indicate if changes were made.

\section{References}

1. Jackson CE, Rosenfeld J, Moore DH, Bryan WW, Barohn RJ, Wrench $\mathrm{M}$ et al (2001) A preliminary evaluation of a prospective study of pulmonary function studies and symptoms of hypoventilation in ALS/MND patients. J Neurol Sci 191(1-2):75-78

2. Bourke SC, Bullock RE, Williams TL, Shaw PJ, Gibson GJ (2003) Noninvasive ventilation in ALS: indications and effect on quality of life. Neurology 61(2):171-177

3. Mustfa N, Walsh E, Bryant V, Lyall RA, Addington-Hall J, Goldstein LH et al (2006) The effect of noninvasive ventilation on ALS patients and their caregivers. Neurology 66(1526-632; 8):1211-1217

4. Bourke SC, Tomlinson M, Williams TL, Bullock RE, Shaw PJ, Gibson GJ (2006) Effects of non-invasive ventilation on survival and quality of life in patients with amyotrophic lateral sclerosis: a randomised controlled trial. Lancet Neurol 5(2):140-147

5. Piepers S, van den Berg JP, Kalmijn S, van der Pol WL, Wokke $\mathrm{JH}$, Lindeman E et al (2006) Effect of non-invasive ventilation on survival, quality of life, respiratory function and cognition: a review of the literature. Amyotroph Lateral Scler 7(4):195-200

6. Hazenberg A, Kerstjens HA, Prins SC, Vermeulen KM, Wijkstra PJ (2014) Initiation of home mechanical ventilation at home: A randomised controlled trial of efficacy, feasibility and costs. Respir Med

7. Hazenberg A, Kerstjens HA, Prins SC, Vermeulen KM, Wijkstra PJ (2014) Initiation of home mechanical ventilation at home: a randomised controlled trial of efficacy, feasibility and costs. Respir Med 108(9):1387-1395

8. Windisch W, Freidel K, Schucher B, Baumann H, Wiebel M, Matthys H et al (2003) The Severe Respiratory Insufficiency (SRI) Questionnaire: a specific measure of health-related quality of life in patients receiving home mechanical ventilation. J Clin Epidemiol 56(0895-4356; 8):752-759

9. Carone M, Bertolotti G, Anchisi F, Zotti AM, Donner CF, Jones PW (1999) Analysis of factors that characterize health impairment in patients with chronic respiratory failure. Quality of Life in Chronic Respiratory Failure Group. Eur Respir J 13(0903-1936; 6):1293-1300

10. Aaronson NK, Muller M, Cohen PD, Essink-Bot ML, Fekkes M, Sanderman R et al (1998) Translation, validation, and norming of the Dutch language version of the SF-36 Health Survey in community and chronic disease populations. J Clin Epidemiol 51(11):1055-1068

11. Zigmond AS, Snaith RP (1983) The hospital anxiety and depression scale. Acta Psychiatr Scand 67(6):361-370

12. Ware JE Jr, Sherbourne CD (1992) The MOS 36-item short-form health survey (SF-36). I. Conceptual framework and item selection. Med Care 30(6):473-483

13. Bourke SC, Tomlinson M, Williams TL, Bullock RE, Shaw PJ, Gibson GJ (2006) Effects of non-invasive ventilation on survival and quality of life in patients with amyotrophic lateral sclerosis: a randomised controlled trial. Lancet Neurol 5(1474-4422; 1474-4422; 2):140-147 